\section{OC-048 ADENOMA DETECTION REDUCES DURING A COLONOSCOPY LIST}

doi:10.1136/gutjnl-2012-302514a.48

R Gao, ${ }^{*}$ G D Corbett, J Lee, F Sampaziotis, E Cameron. Department of Gastroenterology, Addenbrookes Hospital, Cambridge, UK

Introduction Recent studies have provided conflicting data on whether colonoscopy lesion detection varies with time of day. ${ }^{1-3}$ We aimed to assess whether the time of procedure within a list affected polyp and adenoma detection rate (PDR, ADR), surrogate markers for colonoscopy quality, at a busy tertiary centre endoscopy unit in the UK.

Methods All patients undergoing colonoscopy in 2009 were retrospectively identified and included in the study. Patient demographics and colonoscopic findings were obtained from endoscopy and histology reports. Polyp detection rate, adenoma detection rate, polyps per colonoscopy (PPC) and adenomas per colonoscopy (APC) were calculated. Morning and afternoon lists were combined as both are $4 \mathrm{~h}$ long and results were analysed in 20 min segments. Statistical significance was determined by linear regression.

Results During the 12-month study period, 3923 colonoscopy procedures $(60.4 \pm 15.3$ years, $52.7 \%$ female) were performed by 42 endoscopists. 3718 procedures were available for analysis after excluding cases performed in the cross-over period between lists (1300-1400) and out of hours. The average PDR was 35.9\% and the ADR 23.9\%. Although PDR $(p=0.27)$ and ADR $(p=0.24)$ did not vary significantly during the course of a list, PPC ( $p=0.015$, Abstract OC-048 figure 1) and APC ( $p=0.025)$ significantly reduced as lists went on. Results are shown in Abstract OC-048 table 1.

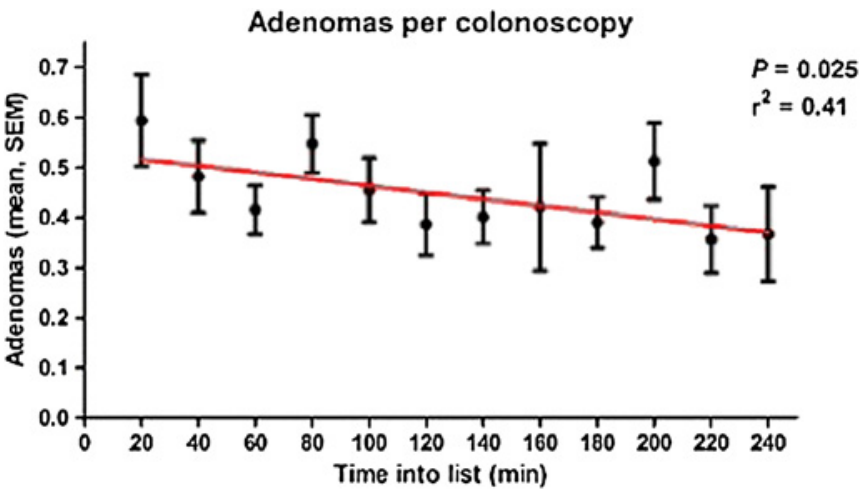

Abstract 0C-048 Figure 1 Linear regression analysis for APC $(p=0.025)$ during the course of a colonoscopy list.

Abstract OC-048 Table 1 PPC and APC at time periods during a list

\begin{tabular}{|c|c|c|c|c|c|c|}
\hline Time into list & $20 \mathrm{~min}$ & $40 \mathrm{~min}$ & $60 \mathrm{~min}$ & $80 \mathrm{~min}$ & $100 \mathrm{~min}$ & $120 \mathrm{~min}$ \\
\hline Cases & 421 & 397 & 380 & 360 & 365 & 367 \\
\hline PPC & 1.08 & 0.81 & 0.82 & 0.95 & 0.80 & 0.70 \\
\hline APC & 0.59 & 0.48 & 0.42 & 0.55 & 0.45 & 0.39 \\
\hline Time into list & $140 \mathrm{~min}$ & $160 \mathrm{~min}$ & $180 \mathrm{~min}$ & $200 \mathrm{~min}$ & $220 \mathrm{~min}$ & $240 \mathrm{~min}$ \\
\hline Cases & 339 & 312 & 270 & 238 & 172 & 97 \\
\hline PPC & 0.70 & 0.75 & 0.66 & 0.90 & 0.68 & 0.64 \\
\hline APC & 0.40 & 0.42 & 0.39 & 0.51 & 0.35 & 0.37 \\
\hline
\end{tabular}

Conclusion The mean number of polyps and adenomas detected falls significantly during the course of a colonoscopy list. Notably, our data shows no difference in the traditional "detection rate" measures ( $\mathrm{ADR}$ and $\mathrm{PDR}$ ) and thus highlights that, in isolation, these may be inadequate measures of colonoscopy quality, and some measure of the number of adenomas detected is also required. The fall in number of adenomas per colonoscopy may relate to operator fatigue and implies that significant lesions could be missed at the end of a list. Further study is required to establish whether revising the length of endoscopy lists or providing a break during a list could prevent this drop off in performance.

Competing interests None declared.

\section{REFERENCES}

1. Gurudu SR, et al. Am J Gastroenterol 2011;106:1466-71.

2. Lee A, et al. Gastrointest Endosc 2011;73:467-75.

3. Munson GW, et al. Gastrointest Endosc 2011;73:476-9.

\section{OC-049 DUODENAL BULB BIOPSIES - ARE THEY A NECESSITY IN COELIAC DISEASE?}

doi:10.1136/gutjnl-2012-302514a.49

${ }^{1} \mathrm{M}$ Kurien, ${ }^{*}{ }^{1} \mathrm{~K}$ E Evans, ${ }^{1} \mathrm{I}$ Aziz, ${ }^{2} \mathrm{~S} S$ Cross, ${ }^{1} \mathrm{~A} \mathrm{D}$ Hopper, ${ }^{3} \mathrm{M}$ Hadjivassiliou, ${ }^{1}$ D S Sanders. 'Department of Gastroenterology, Royal Hallamshire Hospital, Sheffield, UK; ${ }^{2}$ Department of Pathology, Royal Hallamshire Hospital, Sheffield, UK; ${ }^{3}$ Department of Neurology, Royal Hallamshire Hospital, Sheffield, UK

Introduction Historically, Brunner's glands in the bulb were thought to cause histological interpretation difficulties, however recent studies have demonstrated that this area maybe the only site to demonstrate villous atrophy (VA) and thus detect Coeliac Disease (CD). This study evaluates the diagnostic yield of taking duodenal bulb biopsies in coeliac patients compared with controls.

Methods Patients undergoing clinically indicated oesophogastrodudoenoscopy (OGD) were prospectively recruited from a single tertiary referral centre between November 2008 and December 2011. Indications for OGD included positive coeliac serology, family history of coeliac disease, diarrhoea, iron deficiency anaemia, abdominal pain and weight loss. All biopsies were graded using the Marsh criteria, with patients being assigned to one of three groups: Group 1 (CD: New Diagnosis), Group 2 (CD: Remission) and Group 3 (Controls).

Results 550 patients (360 female) with median age 51 (range 15-89 years) were prospectively recruited. 153 had newly diagnosed celiac disease, 91 established celiac disease, and 306 controls. New diagnosis celiac disease $(9 \%, \mathrm{p}<0.0001)$ and established celiac disease $(14 \%, p<0.0001)$ were more likely than controls to have VA in the bulb alone (Abstract OC-049 table 1). Overall, when comparing the histological lesion of the bulb against the distal duodenum, 36/91 $(40 \%)$ with established celiac disease $(p<0.0001)$ and $35 / 153(23 \%)$ newly diagnosed $(\mathrm{p}<0.0001)$ had a discrepancy in the severity of the lesion between the two sites compared with 22/306 (7\%) controls. In all, 28/36 with established celiac disease and 24/35 newly diagnosed had the more severe lesion in the bulb. One patient in the control group had VA. This patient was HIV positive with positive tTG and negative EMA, however the HLA status was incompatible with coeliac disease.

Abstract OC-049 Table 1 Histology, serology in coeliac disease and controls

\begin{tabular}{lrrrrll}
\hline & N & $\begin{array}{l}\text { +ve Coeliac } \\
\text { serology }\end{array}$ & \multicolumn{1}{c}{ VA in D1 } & VA in D2 & $\begin{array}{l}\text { VA in } \\
\text { D1 only }\end{array}$ & $\begin{array}{l}\text { VA in } \\
\text { D2 only }\end{array}$ \\
\hline Controls & 306 & $55(18 \%)$ & $1(0.0 \%)$ & $1(0.0 \%)$ & 0 & 0 \\
CD: new & 153 & $142(93 \%)$ & $146(95 \%)$ & $139(91 \%)$ & $14(9 \%)$ & $7(5 \%)$ \\
CD: remission & 91 & $60(66 \%)$ & $40(44 \%)$ & $29(32 \%)$ & $13(14 \%)$ & $2(2 \%)$ \\
\hline
\end{tabular}

Conclusion This is the largest prospective study evaluating the value of a duodenal bulb biopsy strategy. VA may only be present in the 